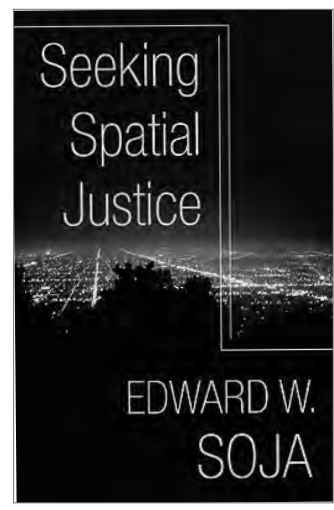

Las cuestiones de justicia no pueden ser vistas independientemente de la condición urbana. No sólo porque la mayoría de la población mundial vive en ciudades, sino, sobre todo, porque la ciudad condensa las múltiples tensiones y contradicciones de la vida moderna (traducción propia). Esta cita, de Erik Swyngedouw (Divided Cities, 2006), vincula explícitamente, desde las primeras páginas del libro, la relación entre justicia y ciudad. Es decir, se antepone una condición espacial de la ciudad para comprender la vida social. El equilibrio implícito entre espacio y sociedad es finalmente uno de los aspectos fundamentales del libro y apunta a reformular el concepto tradicional de justicia.

Por lo tanto, se trata de explorar la idea de justicia espacial como un concepto teórico, punto de focalización para el análisis empírico y objetivo para la acción política y social, entendiendo que la idea de justicia, en cualquier definición, tiene implicancias geográficas y expresión espacial, más allá de una serie de atributos físicos que puedan ser mapeados. Tradicionalmente, la dimensión espacial ha sido tratada como un antecedente fijo,

\section{Seeking Spatial Justice}

\author{
Edward W. Soja
}

Globalization and Community Series. UniversiTy of Minnesota Press 2010

un ambiente físico que, si bien tiene alguna influencia en nuestra vida, remite a una característica externa al mundo social. Se ha privilegiado el pensar históricamente más que geográficamente.

Sin embargo, el autor plantea insistentemente el advenimiento de una dialéctica socioespacial, un giro espacial en el pensamiento y comprensión de los fenómenos sociales. La idea es preguntar cómo el espacio está involucrado en generar y sostener diferentes procesos de desigualdad, injusticia, explotación, racismo, sexismo, etc. El objetivo es estimular nuevas formas de pensamiento y acción para cambiar las geografías injustas en las que vivimos.

En este sentido, no se trata de reemplazar las condicionantes sociales o históricas, pero sí de equilibrar la importancia del espacio. Todo lo que es social, es simultánea e inherentemente espacial. Así, el pensamiento espacial, entendido como una visión más amplia del proceso de urbanización, vincula la búsqueda por justicia espacial con las presiones y la lucha sobre lo que se ha llamado el derecho a la ciudad. 
A partir de estas premisas generales, el libro se estructura en seis capítulos. Los primeros tres exponen las ideas teóricas del autor y precisan la relación planteada entre justicia y espacio. Los tres capítulos finales intentan encontrar una base empírica de casos particulares, comenzando por la ciudad de Los Ángeles, para vincular teoría y práctica. Sin embargo, este objetivo no se concreta, y la profundidad conceptual alcanzada hasta el tercer capítulo se diluye en ejemplos y anexos poco relevantes. Por último, el libro de Soja es un complemento teórico importante para comprender una serie de reflexiones e investigaciones contemporáneas acerca de la relación entre justicia y ciudad. Entre otras, cabe señalar los aportes de Fainstein (2010): "The just city"; Marcuse et al. (2009): "Searching for the just city. Debates in urban theory and practice"; Harvey (2009): "Social Justice and the city. Geographies of justice and social transformations", etc. A diferencia de los anteriores, el libro de Soja intenta una perspectiva espacial crítica, no normativa ni utópica, distanciándose, por ejemplo, de las ideas de ciudad justa, predominante en los teóricos de la planificación.

\section{Espacio}

El giro espacial propuesto por el autor se refiere a una difusión sin precedentes de un pensamiento espacial crítico sobre una amplia gama de cuestiones. El giro espacial da pie a una conciencia espacial que supera el mundo académico y las metáforas pequeñas asociadas al territorio y busca generalizar una justicia espacial, así como difundir las ideas de derecho a la ciudad. Además, pretende equilibrar el supuesto de predominancia del tiempo como factor estructurante de la vida social, proponiendo que la existencia espacial y temporal tienen una equivalencia ontológica, así como una equivalencia en el poder explicativo de diferentes fenómenos sociales y su significancia en el comportamiento. No existiría una razón a priori para hacer más importante una dimensión que otra.
En este sentido, la espacialidad aparece como un producto social complejo, creado colectivamente, configurado y socializado, que define nuestro hábitat. Dicho espacio socializado crea nuestra biografía y geohistoria. Para Soja, la vida humana es espacial, temporal y social, simultánea e interactivamente, por lo que está siempre comprometida en una dialéctica socioespacial. Sin embargo, tradicionalmente se ha dado mayor énfasis en cómo lo social configura o determina lo espacial y no al revés, es decir, en cómo lo espacial configura o determinan lo social en diferentes dimensiones, tanto en la inmediatez de las relaciones interpersonales, hasta las relaciones de clase y de estratificación social.

Así como con la relación entre espacio y tiempo, lo social y lo espacial estarían dialécticamente entrelazados, mutuamente, problemáticamente, formativa y consecuentemente. Luego no existiría un fondo (background) muerto o un espacio físico neutro para la vida social. Al contrario, en la nueva conciencia espacial la geografía en la que estamos insertos puede intensificar o atenuar procesos de explotación económica, dominación política y cultural, así como diferentes formas de discriminación. Sin este reconocimiento, el espacio pasa a ser simplemente un escenario. Siguiendo este argumento, el autor propone un espacio siempre lleno de fuerzas políticas e ideológicas, que definen y forman nuestra vida y nos desafían a involucrarnos en las luchas por el espacio. De esto trata precisamente la dimensión política de la justicia espacial.

\section{Justicia}

La idea de justicia en este texto está emparentada con otros conceptos importantes referidos a la construcción de una sociedad justa, como: libertad (freedom/liberty) equidad, igualdad, democracia, derechos civiles, etc. Sin embargo, la búsqueda de justicia aparece como un objetivo más fuerte y plausible que sus alternativas. 
Para Soja, las alternativas al concepto de justicia presentan una serie de problemas. La búsqueda de libertad tiene matices conservadores, en el sentido de la libertad de elección. La idea de libertad como liberación suena algo pasado de moda. Igualdad aparece como un objetivo inalcanzable y abstracto, etc. Por lo tanto, para muchos, las políticas orientadas a la idea de justicia aparecen como ideas nuevas, inclusivas y arraigadas, que permiten movilizar la acción colectiva en el territorio.

En este contexto, las razones del auge de la idea de justicia como objetivo político están dadas particularmente por las consecuencias negativas de la globalización y la constitución de la nueva economía. Específicamente en ámbitos sociales, políticos, culturales y medioambientales, la globalización ha multiplicado las desigualdades preexistentes en la sociedad contemporánea (ricos-pobres; hombres-mujeres; diferencias raciales, etc.), lo que ha derivado en un "localismo militante", en referencia a D. Harvey. Estos movimientos sociales y espaciales han extendido la politización de la justicia en diversos ámbitos y escalas, transversalmente y superando las categorías binarias tradicionales. Así, la espacialización de la búsqueda de este concepto de justicia es efectiva en proveer un vínculo organizacional que permita mantener la asociación y movilización a nivel territorial.

Específicamente, "el reconocimiento de que el espacio importa, ofrece nuevas pistas, no sólo de cómo la injusticia es producida a través del espacio, sino también cómo el análisis espacial de la injusticia puede avanzar en la luch a por justicia social, informando las demandas concretas y las prácticas que visibilizan dichas demandas" (traducción propia) en referencia a la editorial de Critical Planning de 2007.

\section{Geografías}

El cuerpo y el planeta aparecen como los dos extremos y límites del concepto de justicia espacial. Sin embargo, lo que interesa son las consecuencias, atribuibles a la geografía, que están en el medio de estos límites, en una escala asociada a las "pequeñas tácticas de habitar", parafraseando a M. Foucault. Para Soja, "focalizar el análisis en ejemplos específicos, dónde y cómo la injusticia se emplaza, ayuda a situar la búsqueda por justicia espacial en contextos socialmente producidos, más allá de dejar flotando el concepto en abstracciones idealizadas, fáciles de desviar en llamados a derechos humanos universales o revoluciones radicalizadas" (p. 31; traducción propia).

Una mirada multiescalar de la ciudad y de la geografía no es común en los estudios urbanos, pero es esencial, según el autor, para comprender el ámbito de aplicación y el poder de interpretación de una perspectiva espacial crítica y de una teoría espacial de la justicia/ injusticia. En este amplio rango de escalas, aparecen desde problemas de segregación, conformación política de los distritos electorales, diferentes formas de segmentación social y control espacial (apartheid), hasta expresiones de la ecología del miedo, privatización del espacio público, derecho inalienable de la propiedad privada etc. Lo que es común a todas estas manifestaciones, es que cuando una determinada injusticia espacial está inscrita en el entorno, es muy difícil de borrar.

Además, existen procesos endógenos de discriminación espacial. La idea de justicia espacial no está configurada sólo por procesos externos y estructurales como los mencionados, a través de la constitución de fronteras territoriales e imposiciones del poder jerárquico. También está configurada desde abajo, a través de procesos endógenos de decisiones de localización y sus consecuencias en la distribución espacial. Evidentemente, la desigualdad en la distribución es la característica más obvia de la injusticia espacial. La geografía urbana está configurada por estos procesos decisionales de diferentes actores. Sin embargo, para Soja, el reconocimiento del carácter social de estos 
procesos geográficos discriminatorios permite concertar la acción social orientada al cambio en múltiples dimensiones y escalas. Así, entre lo local y lo global, aparecen otras escalas regionales, metropolitanas, subnacionales, nacionales, supranacionales, etc. constituyendo cada una nuevos contextos o campos de lucha en la búsqueda de justicia espacial.

\section{Teoría}

Para Soja, toda forma de producción de conocimiento, desde la epistemología a la formulación teórica, el análisis empírico y la aplicación práctica, es siempre simultáneamente e interactivamente social, histórica y espacial, al menos a priori. El giro espacial propuesto consiste, precisamente, en asumir que no hay ninguna razón para entender que nuestra existencia social e histórica es más importante en cualquier sentido que nuestra existencia espacial. Existiría una distorsión ontológica al reducir la existencia sin considerar la dimensión espacial. Identificar esta distorsión y presentar una alternativa, es esencial para el objetivo de desarrollar una teoría útil de justicia espacial. Además, una perspectiva espacial crítica, derivada en teoría, está concebida en su uso práctico como elemento de liberación, más que orientado a una concepción normativa del espacio o a la búsqueda de una verdad espacial.

Así, de esta triple dialéctica se pueden derivar una serie de principios que describen la espacialidad de la vida humana. Los procesos sociales no se espacializan uniformemtte. Nuestras acciones y actividades tienden de una u otra manera a ser nodales, focalizadas alrededor de un centro particular o aglomeración, y esta centralidad o carácter nodal generará una distribución desigual de ventajas y desventajas dependiendo de la localización y accesibilidad respecto a dicho centro o nodo. Por otro lado, la vida humana no sólo está configurada por desigualdades geográficas, sino que esta configuración juega un rol en producirlas y reproducirlas. En este sentido, la teorización del espacio da pie a una teorización de la justicia/injusticia. Se propone así, un concepto de justicia expandido, que supera las fronteras de la discusión legal para discutir los principios generales de lo justo y de la democracia en relación con el espacio y el territorio.

Intentado comprender y actuar en base a este potencial de la ciudad como espacio de reivindicación, se estimulan tres formas de pensar los aspectos espaciales y geográficos de la injusticia. La primera, apunta a focalizar específicamente la justicia espacial, enfatizando una dialéctica más balanceada entre sus causas sociales y espaciales. La segunda, apunta a construir una noción de justicia territorial basada por un lado, en una formulación liberal de los estudios geográficos de la desigualdad y el bienestar social y, por otro, tomando una posición radical a través de la geografía marxista y los estudios críticos acerca de la urbanización de la injusticia. La tercera, emerge de las ideas de H. Lefebvre acerca del derecho a la ciudad, como un significante de la nueva teorización radical de la espacialidad.

Así, cada vez más, existiría una conciencia de que la espacialidad humana en todas sus formas y expresiones es socialmente producida y la teoría debe dar cuenta de aquello.

\section{Los Ángeles}

En el contexto de la reestructuración económica y la globalización del capital, del trabajo, la cultura y otras fuerzas de cambio que han reconfigurado las metrópolis en todo el mundo en los últimos años, Los Ángeles (L.A.) aparece como un ejemplo de la radicalización de estos procesos. El autor sitúa a 
L.A. como el lugar donde el conocimiento local y la conciencia regional animan una perspectiva multiescalar, vinculando movimientos locales con movimientos de justicia globales y la reactivación de las luchas por el derecho a la ciudad. El proceso de traducción de una teoría espacial crítica a una práctica concreta en el territorio, genera también nuevos desafíos, entre otros:

- Comenzar un proceso para construir una capacidad colectiva de las luchas urbanas locales para convertirlas en movimientos nacionales en función del derecho a la ciudad.

- Proveer un marco y una estructura de organización regional que vincule a los intelectuales.

- Construir una alianza y red nacional que permita el aprendizaje y conocimiento de las organizaciones, creando debates sobre los problemas que afectan a las comunidades urbanas.

Finalmente, L.A. aparece como el ejemplo más cercano al autor, pero que puede transformarse en prácticamente cualquier ciudad metropolitana contemporánea. El desafío es entonces articular multiescalarmente diferentes movimientos y ciudades en una lógica dialéctica socioespacial. En este sentido, el libro busca abordar el futuro desde una perspectiva espacial crítica, a través de una interpretación espacial de los sucesos, que responden a nuevas contradicciones, atribuibles particularmente al capitalismo neoliberal, donde las crisis (post 70s) han sido eminentemente crisis urbanas. IEURE

\section{Felipe Link L.}

Sociólogo, Doctor en Areuitectura y Estudios URBANOS.

Académico Escuela de Sociología, Universidad

Diego Portales. Contacto: Facultad de

Ciencias Sociales e Historia, Ejército 333 piso 2,

SANTiago-Chile.E-MaIL: Felipe.Link@UdP.Cl 